\title{
Changes of the properties of oil-polluted soils after recultivation (remediation) on the northern territories of the Russian Federation (the Republic of Komi)
}

\author{
Zakhar Ezhelev*, Aminat Umarova, Ludmila Lysak, Julia Zavgorodnyaya
}

Lomonosov Moscow State University, Faculty of Soil Science, Moscow, Russia

\begin{abstract}
Soil petroleum pollution is characteristic for soils of many petroleum-producing countries. The success of recultivation of such soils is determined by the speed and quality of cleaning and further propertiestransformation of recultivated soils. Our work is devoted to the examination of properties of recultivated more than 20 years ago petroleum polluted soils. We defined physical and chemical properties and regimes of soils,, fractional composition of the hydrocarbons of petroleum, the total population and the taxonomic structure of saprotrophic bacterial complex.

\section{Article Info}

Received : 01.07.2014

Accepted : 13.03 .2015 It was shown that the ability of the studied recultivatedsoils to self-purification from anthropogenic hydrocarbons is determined by a combination of such a factors: 1- landscape position and removal of organic pollutants by surface water, 2 -fractional composition of hydrocarbons, 3 - biodegradation and level of initial contamination with hydrocarbons. It was found that the direction and intensity of the soils evolution is primarily due to the degree of soil initial properties and regimes transformations during the recultivation procedure.
\end{abstract}

Keywords: soil, oil pollution, remediation

(c) 2015 Federation of Eurasian Soil Science Societies. All rights reserved

\section{Introduction}

Research of transformation of the oil-polluted soils after carrying out their remediation is extremely actual. It is connected with increase of scales of extraction and transportation of oil, since it is the important energy resource. Secondly, it is connected with extremely difficult structure of a pollutant, representing by hundreds various compounds of hydrocarbons and the heterocyclic compounds containing nitrogen, oxygen, sulfur and microelements. Thirdly, it is connected with the features of oil's receipt and impact on the environment, as a rule, simultaneous and comprehensive. During the pollution of environment not only the pollution of the soil surface happens, but also happen disruption of its water-air and temperature regimes, change of soil structure, transfer of toxic substances in landscape and etc. Soils and climatic conditions of the territory have the most important meaning in remediation of oil-polluted soils. All of the above leads to the necessity of development of different methods of soil remediation and study their after effect.

Most studies of the soil cover after carrying out remediation aimed at the study of residual quantities of pollutants, nutrients, soil biological activity. However, during using the biological stage of work with the sowing of crops in the remediation is very important to ensure optimal agro-physical properties of soils. Exactly agro-physical properties are basic parameters of water and temperature regimes, which provide the success of the growth and development of plants Extremely actual this question is for conditions of the

\footnotetext{
${ }^{*}$ Corresponding author.

Lomonosov Moscow State University, Faculty of Soil Science, Department of Soil Physics and Reclamation, Moscow, Russia

Tel.: +74959392542

E-mail address: ejelevsoil@gmail.com

e-ISSN: $2147-4249$

DOI: http://dx.doi.org/10.18393/ejss.2015.4.253-258
} 
north, which are characterized by low temperatures during the whole year, a short growing season, the high proportion of water areas.

The aim of our work is to investigate the transformation of the agro-physical properties of polluted and remediated soils in conditions of north. The following tasks were defined:

1) To study basic agro-physical properties of the non-polluted soil and soil, recultivated by different methods;

2) To investigate the relationship of agrophysical properties' transformation of tundra-gley soils with the basic biological and chemical properties and features of pollution by oil products;

3) To devote the most perspective methods of remediation of oil-polluted soils in the conditions of the North of Russia.

\section{Material and Methods}

The researches were conducted in the Usinsk area, which located in the Northern part of the Republic of Komi (66 degrees $25 \mathrm{C}$ s. and $67^{\circ} 18^{\prime} \mathrm{e}$ d), in the subzone of Northern taiga and forest-tundra. The object of study was the soil cover in the area of 76,5 hectares near the oil pipeline "Vozei - Headworks". At the site in 1994 there was a major emergency as a result of which, according to various estimates, from 60 to 150 thousand tons of crude oil has fallen in the environment. In the period from 1994 to 2010 works on the recultivation of the territory were carried out by different methods.

In this work 4 types of remediation will be considered: (1) Rinsing of polluted soils on a specialized system for processing of oil sludge, which consists in washing in $0.5 \%$ solution biodegradable surfactants at a temperature as $75^{\circ} \mathrm{C}$; (2) Flush and collection of oil from the surface of the soil and the overlapping of the remaining; (3) The replacement of polluted layer of soil by sandy with accommodation on its surface the mix of treated soil, mixed with precipitation of sewage (in the ratio 10:1) capacity of 15-30 cm; (4) Partial flush and oil collection without the overlapping of the remaining. In this variant the cut was laid on the polluted area, directly under the oil slick. For variants 1, 2, 3 were conducted agricultural activities: the harrowing; mineral fertilizers; the sowing of cereals. All variants of the remediated soils are limited in perimeter by pit with depth of $0.5-1 \mathrm{~m}$ to reduce the level of subsoil water.

Soil cuts were conducted, were made their morphological description, description of vegetation cover. In soil samples were determined physical (Shein and Karpachevsky, 2007), chemical (Vorobyova, 2006), biological properties. The total number of bacteria and the structure of saprophytic bacteria was determined in accordance with the techniques developed at the Department of biology at the MSU soils (Andreyuk, 1982).

Analyses of hydrocarbon content and composition were performed by gas chromatography using 6890N GC equipped with flame ionization detector and DB- $1 \mathrm{~ms}$ capillary column $(30 \mathrm{~m} \times 0.25 \mathrm{~mm} \times 0.25 \mu \mathrm{m})$. Content of total petroleum hydrocarbons (TPH), content of diesel range fraction $\left(\mathrm{C}_{14}-\mathrm{C}_{23}\right)$ and waste oil fraction $\left(\mathrm{C}_{24^{-}}\right.$ $\mathrm{C}_{34}$ ) were calculated. Ratio of $\mathrm{C}_{14}-\mathrm{C}_{23}$ to $\mathrm{C}_{24}-\mathrm{C}_{34}$ fraction content was used to characterize the intensity of migration of oil products. Low relative content of diesel range fraction in oil-polluted soil indicated landscape conditions, which provided prevalence of hydrocarbon removal over their accumulation.

\section{Results and Discussion}

Consider the granulometric composition of soils, as the main base of the classification characteristics of soils. Non-polluted soil peafy-gleysol consists of the upper layer of peat with the capacity $20-30 \mathrm{~cm}$, underlain by sandy layer. Prevailing fraction of mineral horizon is fine sand, with a depth there is a decrease in the share of medium and coarse sand and increase thin fractions (Figure 1). By classification of Kachynski (Shein and Karpachevsky, 2007) the granulometric composition changes with the depth from consolidated sand to loam.

Most close to non-polluted soil is 4 types of investigated soil, in which there was not dislocation of soil layers. Granulometric composition of others remediated soils depended on the method of recultivation, capacity of top layer, which was anthropogenically generated. From the depth of $40-50 \mathrm{~cm}$ all variants are identical non-polluted soil. 


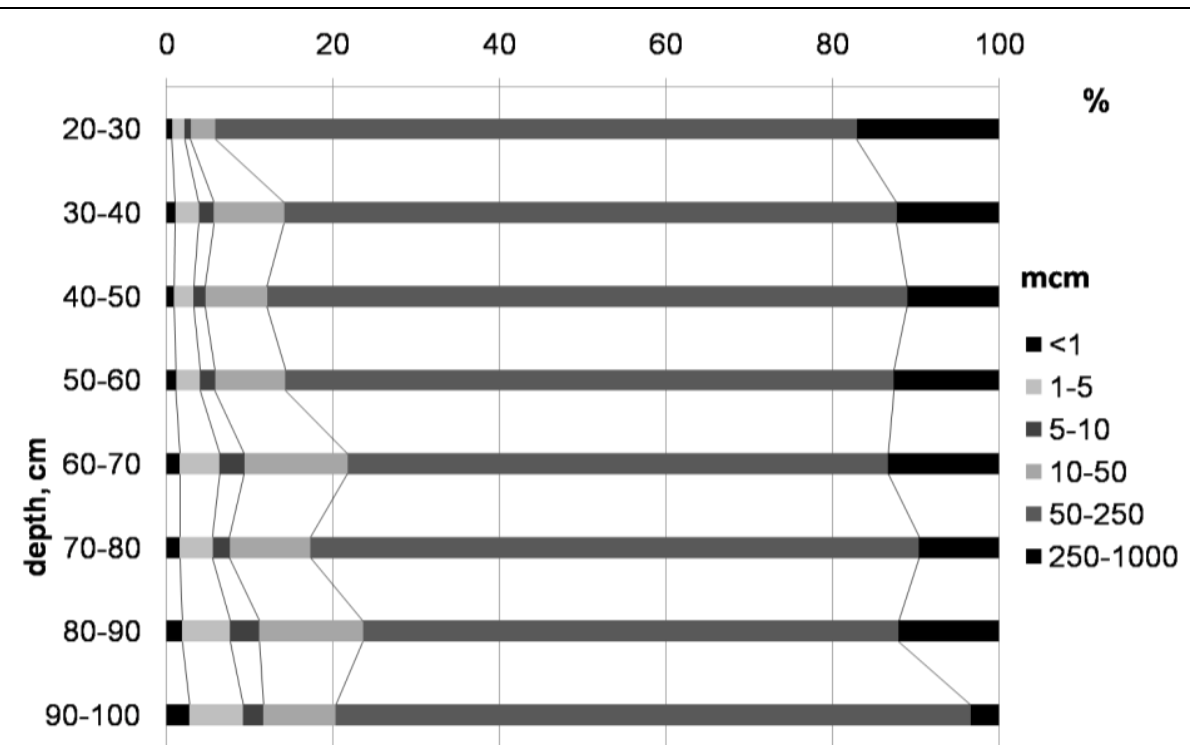

Figure 1. The distribution of granulometric composition of fractions in profile of non-polluted soil

Determination of the density of non-polluted soil also was carried out from the depth of $20 \mathrm{~cm}$ (Figure 2a), the values near $1.7 \mathrm{~g} / \mathrm{cm}^{3}$ are consistent with the data on granulometric composition. For all reclaimed soils relatively low values of density in top horizon are characterized. In 1 variant was a gradual increase density with depth, which connected with technological features of method. In 2 variant, with overlapping the oil, the upper $10 \mathrm{~cm}$ had low values, which is connected with plowing and harrowing. The sharp increase in the density connected with formation plough pans at passage of heavy technicians. In 3 variant density distribution along profile is similar to 2 variant, though with a shift towards higher value because of the less depth and more heavy mechanical composition during introduction of precipitation of sewage. The variant 4, reclaimed by partial oil collection from surface, from depth of $20 \mathrm{~cm}$ is similar to non-polluted soil (Figure 2a). Almost for all layers of all variants values of coefficients of filtration had very high magnitude (Figure $2 \mathrm{~b}$ ), due to high content of peat in top horizons and high content of sand in lower horizons

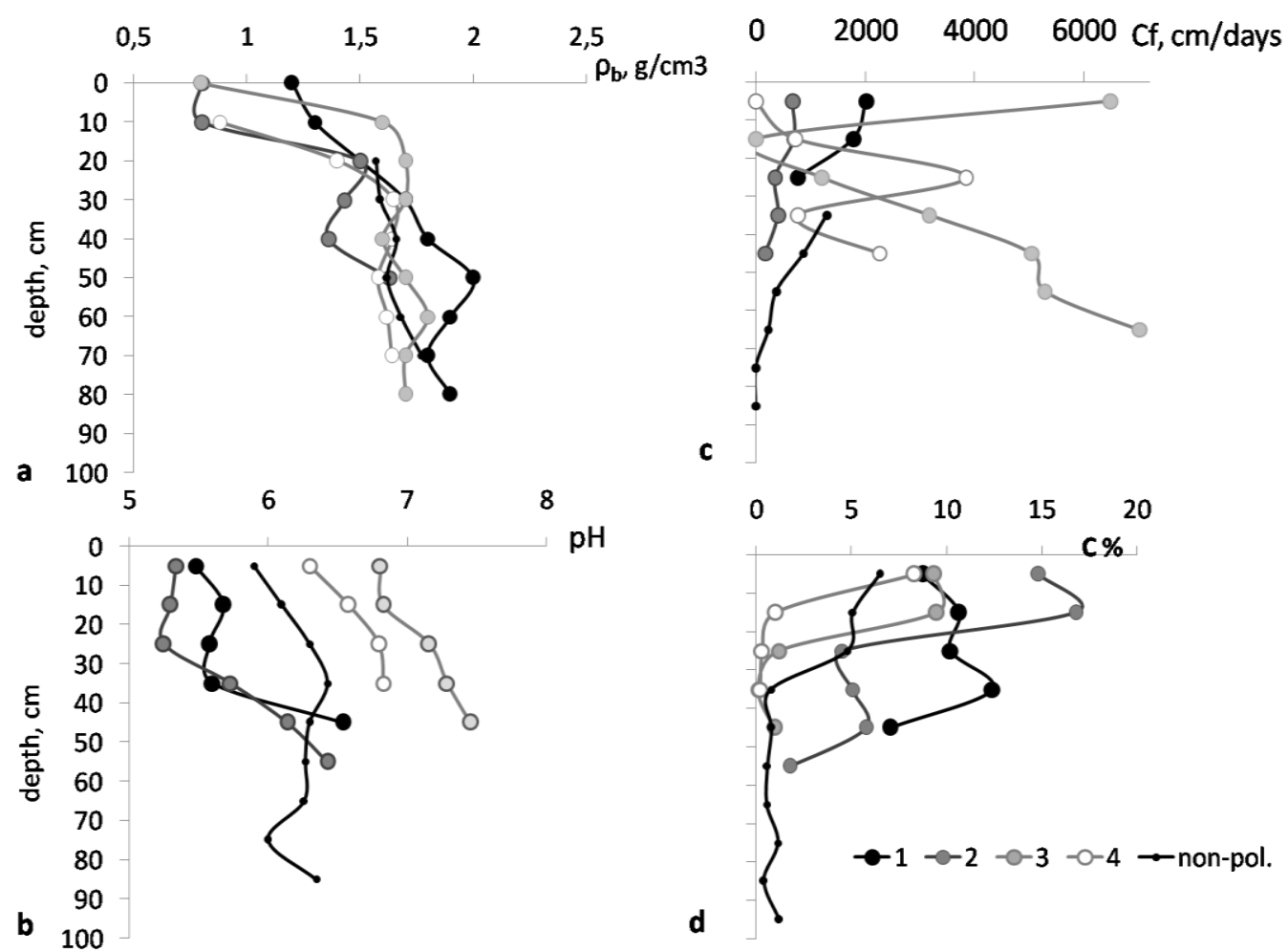

Figure 2. Profile distribution of physical and chemical properties of soils: a) density; b) coefficient of filtration; c) pH; d) content of carbon 
Most close to non-polluted soil is 4 types of investigated soil, in which there was not dislocation of soil layers. Granulometric composition of others remediated soils depended on the method of recultivation, capacity of top layer, which was anthropogenically generated.

From the depth of 40-50 cm all variants are identical non-polluted soil.

Determination of the density of non-polluted soil also was carried out from the depth of $20 \mathrm{~cm}$ (Figure 2a), the values near $1.7 \mathrm{~g} / \mathrm{cm}^{3}$ are consistent with the data on granulometric composition. For all reclaimed soils relatively low values of density in top horizon are characterized. In 1 variant was a gradual increase density with depth, which connected with technological features of method. In 2 variant, with overlapping the oil, the upper $10 \mathrm{~cm}$ had low values, which is connected with plowing and harrowing. The sharp increase in the density connected with formation plough pans at passage of heavy technicians. In 3 variant density distribution along profile is similar to 2 variant, though with a shift towards higher value because of the less depth and more heavy mechanical composition during introduction of precipitation of sewage. The variant 4, reclaimed by partial oil collection from surface, from depth of $20 \mathrm{~cm}$ is similar to non-polluted soil (Figure 2a).

Almost for all layers of all variants values of coefficients of filtration had very high magnitude (Figure 2b), due to high content of peat in top horizons and high content of sand in lower horizons.

Noteworthy non-polluted soil gradual reduction of filtration with the depth, which is consistent with data on granulometric composition. In 3 variant with using precipitation of sewage top $20 \mathrm{~cm}$ of soil had very high values of filtration, which fell sharply to zero values at a depth of 10-15 cm, then again sharply increased. This distribution is associated with soil compaction and increasing content of thin fractions (silt and fine dust) at a given depth. In 4 variant, in places where was observed residual oil, filtration coefficient of the surface layer has decreased to zero (Figure $2 \mathrm{~b}$ ). The highest values are in the profile of variant 3 due to the strong initial changes in soil properties, introduction of precipitation of sewage. For all the studied soils were observed increased values of carbon in the upper part of the profile (Figure 2d), which is connected with the presence of hydrocarbons in soils, especially in 2 variant with plowing of oil.

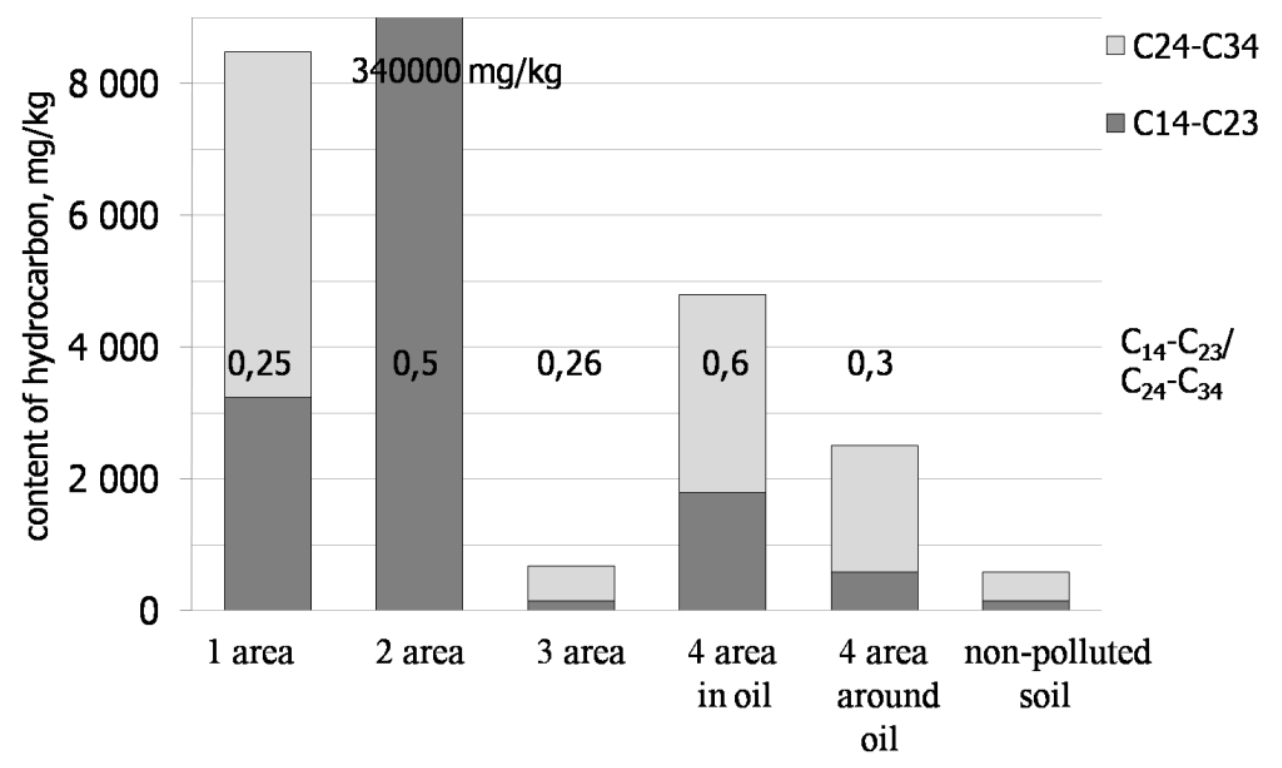

Figure 3. Distribution of fraction of hydrocarbons in the surface horizons of area, remediated by different methods.

Thus, the transformation properties of soils recultivated by different methods, first of all touched the top 40$50 \mathrm{~cm}$ soil thickness. The lower horizons, including through sandy granulometric composition, less underwent a transformation. A significant increase in the density of the upper soil horizons, decrease of the coefficient of filtration is connected with the passage of heavy equipment.

TPH content in the surface horizons of the non-polluted soils did not exceed 581ppm (Figure 3). The lowest TPH value among polluted soils $(681 \mathrm{ppm})$ was observed for the $3 \mathrm{rd}$ area, remediated using sewage precipitations. Higher TPH contents (the order above) were noted in surface soil horizons after 1st remediation method (flushing) and 4th method (partial collection). Maximum content of hydrocarbons 
(339500 ppm) was determined in the soils of the 2nd remediation area, where oil had been plowed instead removing.

The shortcomings of remediation procedure on the 4th areas were expressed in the lateral migration of hydrocarbons around remained oil spills. Soils under oil spills were relatively enriched with diesel range hydrocarbon fraction $\left(\mathrm{C}_{14-23}\right)$, which was found to have low degree of biological degradation. The depth of biodegradation of the initial oil products was evaluated using relative abundance of linear alkanes, which considered to be the least resistant to microbial destruction hydrocarbon fraction.

This hypothesis is confirmed by the indicators of the total number of bacteria, certain direct fluorescent method (the color of the soil suspension by acridine orange) and the structure of saprophytic bacteria(culture GPA environment) (Ezhelev, 2014). Thus, the number of bacteria in 3 rooms with vegetation and without vegetation, was much higher $\left(10^{9}\right)$ than 4 th option (under the oil spill - 108). 3 room were also observed an increase in the diversity of bacteria and the development of bacteria of the genera Rhodococcus and Pseudomonas, known as active destructors oil.

The most detailed studies of the properties of the reclaimed soils were conducted to types 3 . This plot was interesting from the positions of the strong transformation of the components of the landscape. Surface relief during remediation was raised on several meters above the surrounding space with the formation of the slope. A strong change of structure soil was determined by the location of treated soil with precipitation of sewage on powerful sandy layer. Vegetation has been modified by seeding of perennial grasses and planting seedlings of spruce. All this has led to the strong transformation of hydrological and thermophysical conditions of functioning of these soils. On the territory for 4 years of studies had been significant improvement in the quality of the grass cover, and by 2013 decreased the area of bald spots, increased density of the grass. However, draws attention to the difference of conditions in the middle automorphic part of the territory and its hydromorphous edges, where in summer subsoil waters are found at the depth of $40-50 \mathrm{~cm}$.

Both in the upper and lower parts were found large areas without vegetation with black, as if the charred surface painted by hydrocarbons of oil. We examined 4 variants: automorphic with vegetation and without, hydromorphous with vegetation and without it.

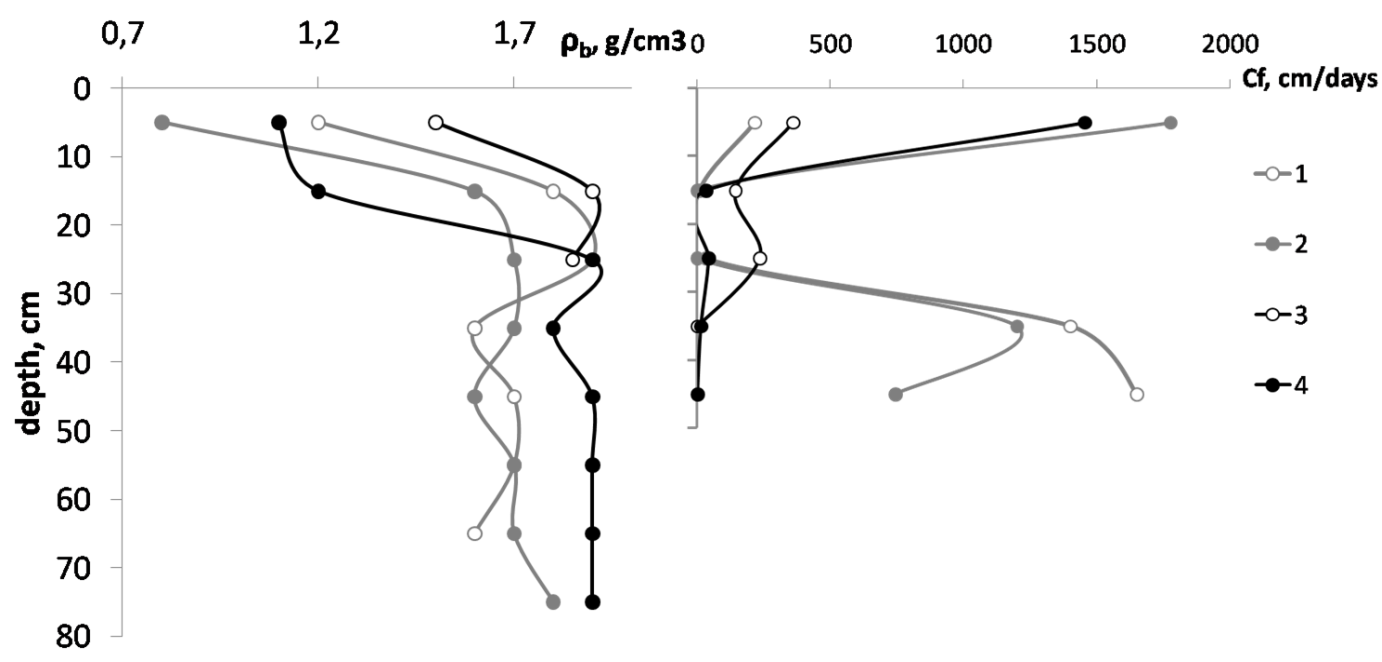

Figure 4. Profile distribution of density (a) and coefficient filtration (b) in 3 variants of remediation. 1- automorphic; 2- automorphic + vegetation; 3- hydromorphic; 4- hydromorphic + vegetation.

The vegetation made values of density decrease in the upper 10-15 cm, and hydromorphous soils in the lower part of the profile had a higher density values (Figure 4a). Note that the soil in places of bald spots without vegetation filtrated moisture from the surface of almost an order of magnitude slower than with vegetation (Figure 4d). The filtration coefficient in almost all variants decreases to zero at a depth of 15-25. Exception was variant of hydromorphic soils in which such reduction was observed at the depth of $30 \mathrm{~cm}$. The research profile of the distribution of filtration in soils have suggested that the slow movement of moisture on the surface of basalt clay can lead to the change of the vertical water transport to the lateral. 


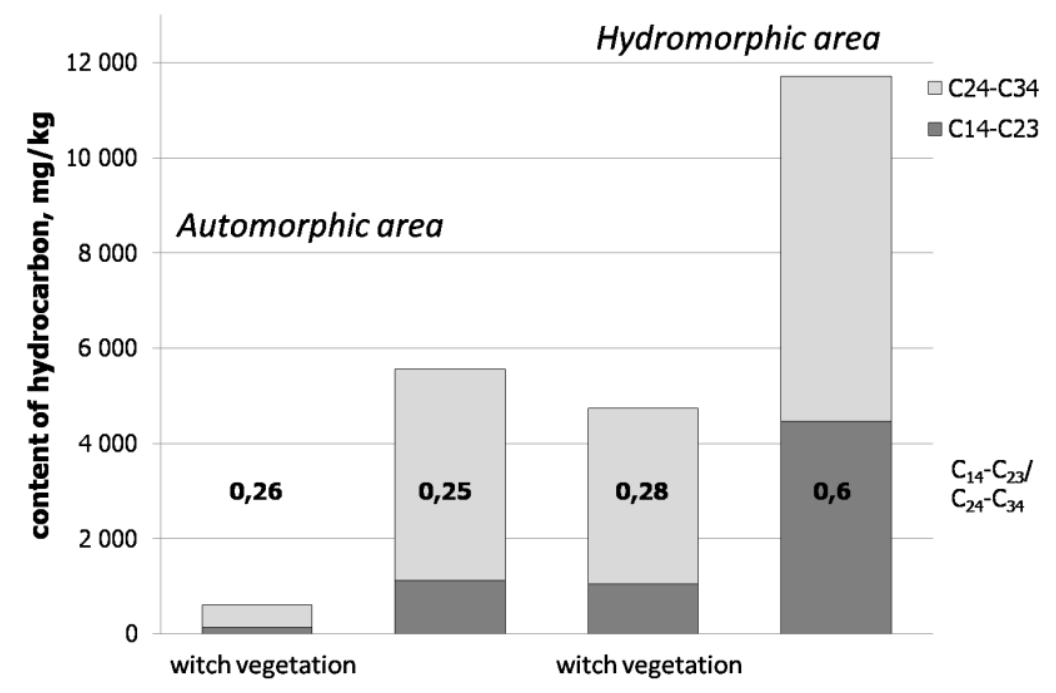

Figure 5. Lateral distribution of hydrocarbons fractions in the surfaces horizons down the slope from West to East on the variant 3 .

Together with surface water streams various mineral and organic substances, including hydrocarbons, can be moved. Thus, the fractional composition of hydrocarbons in the surface soil horizons showed, that in local depressions with hydromorphic conditions TPH content is significantly higher than for automorphic sites (Figure 5). Similar trend was found for $\mathrm{C}_{14}-\mathrm{C}_{23}$ fraction. Increasing of the $\mathrm{C}_{14}-\mathrm{C}_{23} / \mathrm{C}_{24}-\mathrm{C}_{34}$ ratio in soils of open hydromorphic sites indicated the relative accumulation of diesel range fraction due to lateral migration process and low biodegradation rate in aerobic conditions. This corresponds with the data of Solntseva N.P. (Solntseva, 1998), indicating the possibility of the relative accumulation in depressions of light oil fractions simultaneously with their intensive removal from soils of overlying landscape positions.

\section{Conclusion}

Thus, field and laboratory studies have found an extremely high diversity of physical and chemical soil properties, preserved to the present time and is caused, first of all, the specifics of events held during cleaning of soil cover. Identification and analysis of the agrophysical properties of the reclaimed soils showed that the changes of the properties of the solid phase of soil and the presence of hydrocarbons in soil profile lead to a different regime of functioning of soils and its further transformation.

The analysis of the content of residual quantities of oil products in soils showed that the highest content of oil fractions, able to migration, is contained in those variants of soils, which was used oil collection from the surface. The concentration of oil products in these areas, apparently, due to the specifics of the water regime of soils and terrain features. Sites on which was cutting the polluted land, its treatment and further return to the original place, dominated by high-boiling most inert fraction of oil products.

On the basis of obtained results it can be argued that in conditions of the North the most effective ways of purification of soil from oil products on the biological stage is the seeding of perennial grasses, the application of mineral and organic fertilizers.

\section{Acknowledgements}

This work supported by the Russian Foundation for Basic Research, project No. 13-04-00034

\section{References}

Andreyuk, E.A. (ed). 1982. Instrumental methods of microbiology of soils. Kiev: Nauk. Dumka. 94 p.

Vorobyova, L.A. 2006. Theory and practice of the chemical analysis of soils. M.: GEOS. $400 \mathrm{p}$.

Solntseva, I.E. 1998. Production of oil and geochemistry of natural landscapes. M.: MSU. 376 p.

Shein, E.V., Karpachevsky, L.O. (eds). 2007. Theories and methods of physics of soils. M.: MSU. 616 p.

Ezhelev, Z.S., Umarova, A.B., Lysak, L.V., 2014. Transformation of the properties of oil-contaminated tundra-gley soils at their remediation with different methods. Bulletin of Altai State Agricultural University. 6: 75-79. 